\title{
AVALIAÇÃO DA INSPEÇÃO SANITÁRIA E ALTERAÇÕES ANATOMOPATOLÓGICAS DE SUÍNOS NO ESTADO DO ACRE, AMAZÔNIA OCIDENTAL, BRASIL
}

Sara Sabrina Lima da Silveira ${ }^{1}$, Tamyres Izarelly Barbosa da Silva ${ }^{2}$, Cassio Toledo Messias $^{3}$, Raimunda Beserra da Silva ${ }^{4}$, Celia Ruth Camilo Nascimento ${ }^{5}$

${ }^{1}$ Médica veterinária do Departamento de Inspeção de Produtos de Origem Animal (DIPOA) - Ministério da Agricultura, Pecuária e Abastecimento (MAPA), Rio BrancoAC, Brasil.

${ }^{2}$ Professora Doutora do Curso de Medicina Veterinária da Universidade Federal do Acre (UFAC), Rio Branco-AC, Brasil. E-mail: tamyres_ibs@hotmail.com

${ }^{3}$ Professor Mestre do Curso de Medicina Veterinária da Universidade Federal do Acre (UFAC), Rio Branco-AC, Brasil.

${ }^{4}$ Médica veterinária da Dom Porquito Agroindustrial, Brasileia-AC, Brasil.

${ }^{5}$ Médica veterinária autônoma, Rio Branco-AC, Brasil.

Recebido em: 15/05/2020 - Aprovado em: 15/06/2020 - Publicado em: 30/06/2020 DOI: 10.18677/EnciBio_2020B8

\section{RESUMO}

O Brasil é um grande exportador de carne suína no mundo. A atribuição de fiscalizar e manter os produtos cárneos em condições higiênico-sanitárias adequadas é realizada pelos serviços de inspeções municipal, estadual ou federal, fundamentando-se em normativas específicas e para garantir a inocuidade dos alimentos ao mercado consumidor. Neste contexto, objetivou-se avaliar a inspeção sanitária e as alterações anatomopatológicas de suínos no estado do Acre, Amazônia Ocidental, Brasil. O estudo foi realizado em abatedouros de suínos, localizados nos municípios de Brasiléia e Rio Branco, Acre. Realizou-se a inspeção ante-mortem e post-mortem dos animais abatidos e todos os dados referentes às alterações nas vísceras e carcaças, além das condições higiênico-sanitárias de cada estabelecimento, foram introduzidos em fichas para acompanhamento. Em todos os abatedouros houve a ocorrência de contaminação, bem como alterações pulmonares. O abatedouro de suínos sob inspeção federal apresentou maior notificação de lesões e melhores condições higiênico-sanitária do estabelecimento, comparando-se aos demais abatedouros sob outras inspeções. Conclui-se que existe uma intensa disparidade higiênico-sanitária entre os estabelecimentos de abate de suínos sob inspeção federal, estadual e municipal do estado do Acre, e que não existe padronização rígida quanto aos procedimentos operacionais durante 0 abate nos estabelecimentos de inspeção sanitária estadual e municipal, podendo comprometer a inocuidade dos produtos cárneos de suínos.

PALAVRAS-CHAVE: Amazônia, carne suína, matadouros, saúde pública 


\title{
EVALUATION OF SANITARY INSPECTION AND ANATOMOPATHOLOGICAL CHANGES IN SWINE IN THE STATE OF ACRE, WEST AMAZONIA, BRAZIL
}

\begin{abstract}
Brazil is a major exporter of pork in the world. The attribution of inspecting and maintaining meat products in adequate hygienic-sanitary conditions is carried out by the municipal, state or federal inspection services, based on specific regulations and to guarantee food safety to the consumer market. In this context, the objective was to evaluate the sanitary inspection and anatomopathological changes of pigs in the state of Acre, West Amazonia, Brazil. The study was carried out in swine abattoirs, located in the municipalities of Brasiléia and Rio Branco, Acre. Pre-mortem and postmortem inspection of slaughtered animals were carried out, and all data regarding alterations in viscera and carcasses, in addition to hygienic-sanitary conditions of each establishment, were inserted into records for follow-up. Contamination occurred in all slaughterhouses, as well as pulmonary alterations. The pig slaughterhouse under federal inspection presented a higher notification of lesions and better hygienic-sanitary conditions of the establishment, comparing it to other slaughterhouses under other inspections. It is concluded that there is an intense sanitary-sanitary disparity between pig slaughtering establishments under federal, state and municipal inspection in the state of Acre, and that there is no rigid standardization of operational procedures during slaughter in state sanitary inspection establishments and municipalities and may compromise the safety of pork meat products.
\end{abstract}

KEYWORDS: Amazon, pig meat, slaughterhouses, public health

\section{INTRODUÇÃO}

O Brasil é o quarto país que mais exporta carne suína no mundo. Segundo dados do Instituto Brasileiro de Geografia e Estatística (IBGE, 2018), o número de animais abatidos em 2018 foi de aproximadamente 33 milhões de cabeças. No Estado do Acre, a produção de carne suína é crescente, sendo um cenário importante para geração de renda e empregos na região, principalmente com o surgimento do frigorífico no Alto Acre, no qual se realiza comércio interestadual e vislumbra exportações por meio da Estrada do Pacifíco (ACRE, 2016).

Os serviços de inspeção em âmbito federal, estadual ou municipal devem estar presentes nos estabelecimentos de abate de suínos para fiscalizar e garantir boas condições higiênico-sanitárias das carnes e subprodutos (COSTA, 2015). Os mesmos devem seguir os preceitos previstos no Regulamento de Inspeção Industrial e Sanitária de Produtos de Origem Animal (RIISPOA), portaria 711 de 1995 do Ministério da Agricultura Pecuária e Abastecimento, e, se tratando de bem-estar animal, a Instrução Normativa $n^{\circ} 3$ de 2000 (BRASIL, 1995; BRASIL, 2000; BRASIL, 2017).

Os abatedouros devem ser inspecionados de modo que assegure as adequadas condições higiênico-sanitárias, o que é extremamente importante para evitar a contaminação das carnes. A precariedade de determinados abatedouros, sobretudo municipais e a fiscalização negligenciada são grandes fontes de preocupação, incidindo na falta de garantia da inocuidade das carnes (BRASIL, 1997; BRASIL, 2005). Além disso, muitas alterações post-mortem e anormalidades, as quais poderiam levar à condenação da carcaça e/ou de vísceras, a exemplo das 
contaminações, é ignorada por falta de conhecimento operacional dos agentes de inspeção ou a ausência do médico veterinário no local de abate (BRETAS et al., 2018; EMBRAPA, 2019).

Neste contexto, visando contribuir para indicação de irregularidades que resultam em risco à saúde pública e à economia, objetivou-se, com este estudo, avaliar a inspeção sanitária e as alterações anatomopatológicas de suínos do estado do Acre.

\section{MATERIAL E MÉTODOS}

Entre o período de 2018 a 2019, foi realizada uma avaliação dos

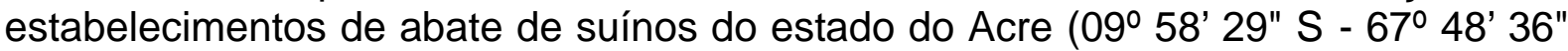
W), sob inspeções sanitárias a nível municipal, estadual e federal, verificando as condições higiênico-sanitárias, os procedimentos operacionais e as alterações postmortem dos animais abatidos (BRASIL, 1995; BRASIL, 2000; BRASIL, 2017). Os frigoríficos estão localizados nos municípios de Rio Branco (inspeção municipal e estadual) e Brasiléia (inspeção federal).

Foram observados os procedimentos, antes e durante todo o abate, desde a condução dos animais, passando pela insensibilização, sangria, escalda, depilação, chamuscamento, evisceração, inspeção post-mortem, acondicionamento e processamento (BRASIL, 2017). As alterações das vísceras e carcaça e higiene das operações foram registradas em ficha própria e fotografadas. Os dados obtidos foram tabulados no programa Excel e submetidos a uma análise estatística descritiva (ROUQUAYROL; GURGEL, 2017).

\section{RESULTADOS}

Durante o estudo, foi observado o abate de 677 suínos em três estabelecimentos no estado do Acre, sendo 587 sob sistema de inspeção federal (SIF), 17 sob inspeção estadual (SIE) e 73 sob inspeção municipal (SIM).

Observou-se no estabelecimento com SIF, condições industriais com alto padrão higiênico-sanitário, treinamento de funcionários para o abate humanitário, presença de programas de autocontrole, procedimentos operacionais adequados, presença de médicos veterinários no setor de controle de qualidade e da inspeção sanitária.

As principais alterações anatomopatológicas notificadas pelo SIF (Fig.1) foram contaminação do trato gastrointestinal $(23,5 \%)$, contaminação das vísceras vermelha (língua - 8,85\%; coração - 8,68\%), aderência pulmonar (13,96\%), fratura $(8,17 \%)$, pneumonia $(8 \%)$, aspiração pulmonar $(6,81 \%)$, cisto renal $(6,3 \%)$ e congestão pulmonar (5,28\%). 
FIGURA 1- Alterações macroscópicas notificadas pelo Sistema de Inspeção Federal no estado do Acre: A) Contaminação das vísceras gastrointestinais; B) Aderência pulmonar; C) Contaminação das vísceras vermelhas e congestão pulmonar; D) Aspiração pulmonar; E) Cisto renal.

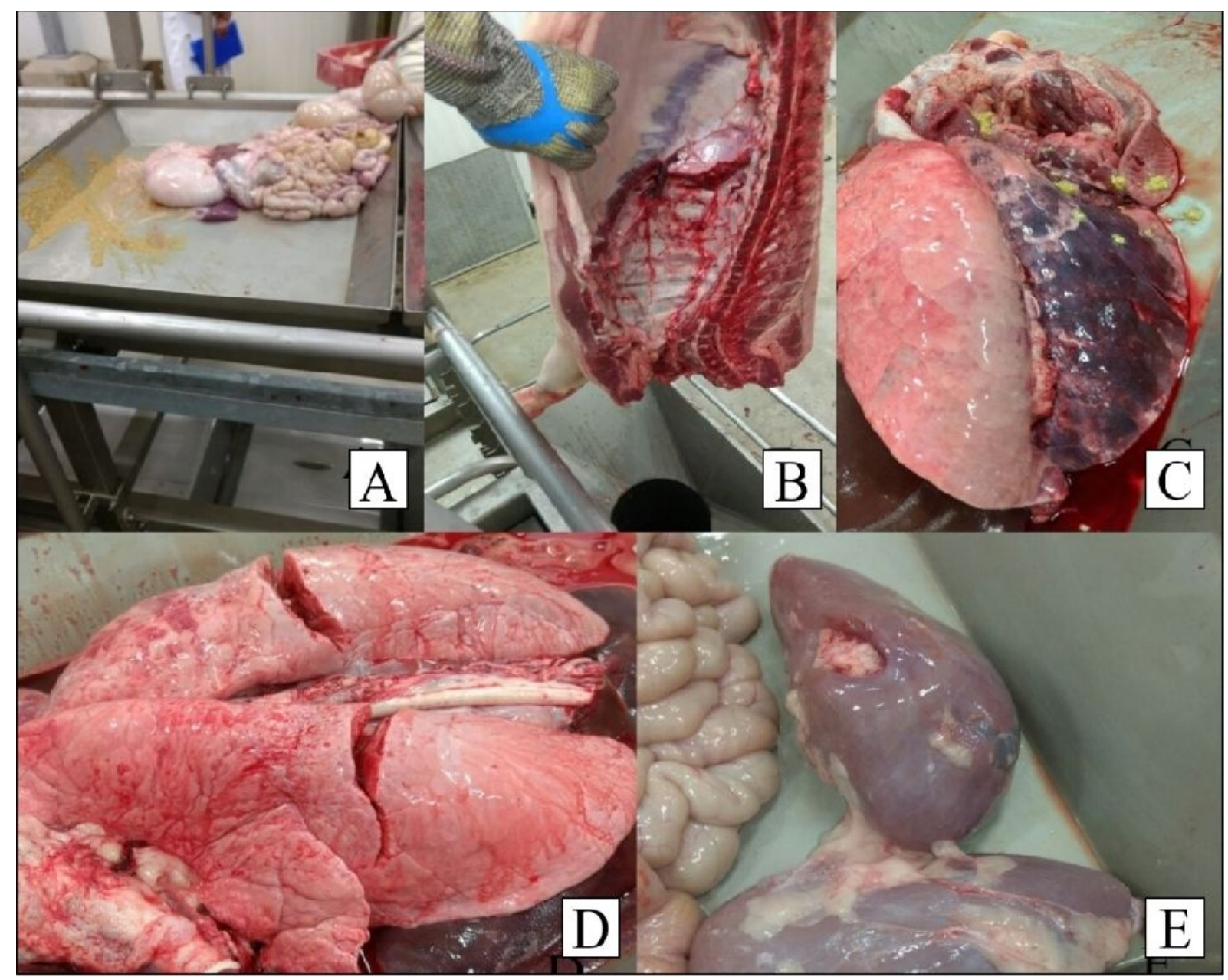

O estabelecimento com SIE, por sua vez, não possuía a estrutura adequada para abate de suínos. Embora houvesse esforço dos funcionários para executar os procedimentos operacionais de forma higiênico-sanitária, o matadouro apresenta falhas em determinados quesitos, como baixa instrução sobre abate humanitário e ausência do médico veterinário no local, havendo apenas agentes de inspeção durante os abates para verificação das lesões. Foi notificado pelo SIE (Fig. 2) a contaminação de carcaças $(35,29 \%)$ e da cabeça $(23,52 \%)$, seguida por congestão pulmonar $(35,29 \%)$ e aspiração pulmonar $(23,52 \%)$. 
FIGURA 2- Abate de suínos sob o Sistema de Inspeção Estadual no estado do Acre: A) Suíno mal insensibilizado e abatido no chão; B) Pulmão pertencente ao animal abatido na figura $A$, apresentando congestão e aspiração de sangue.

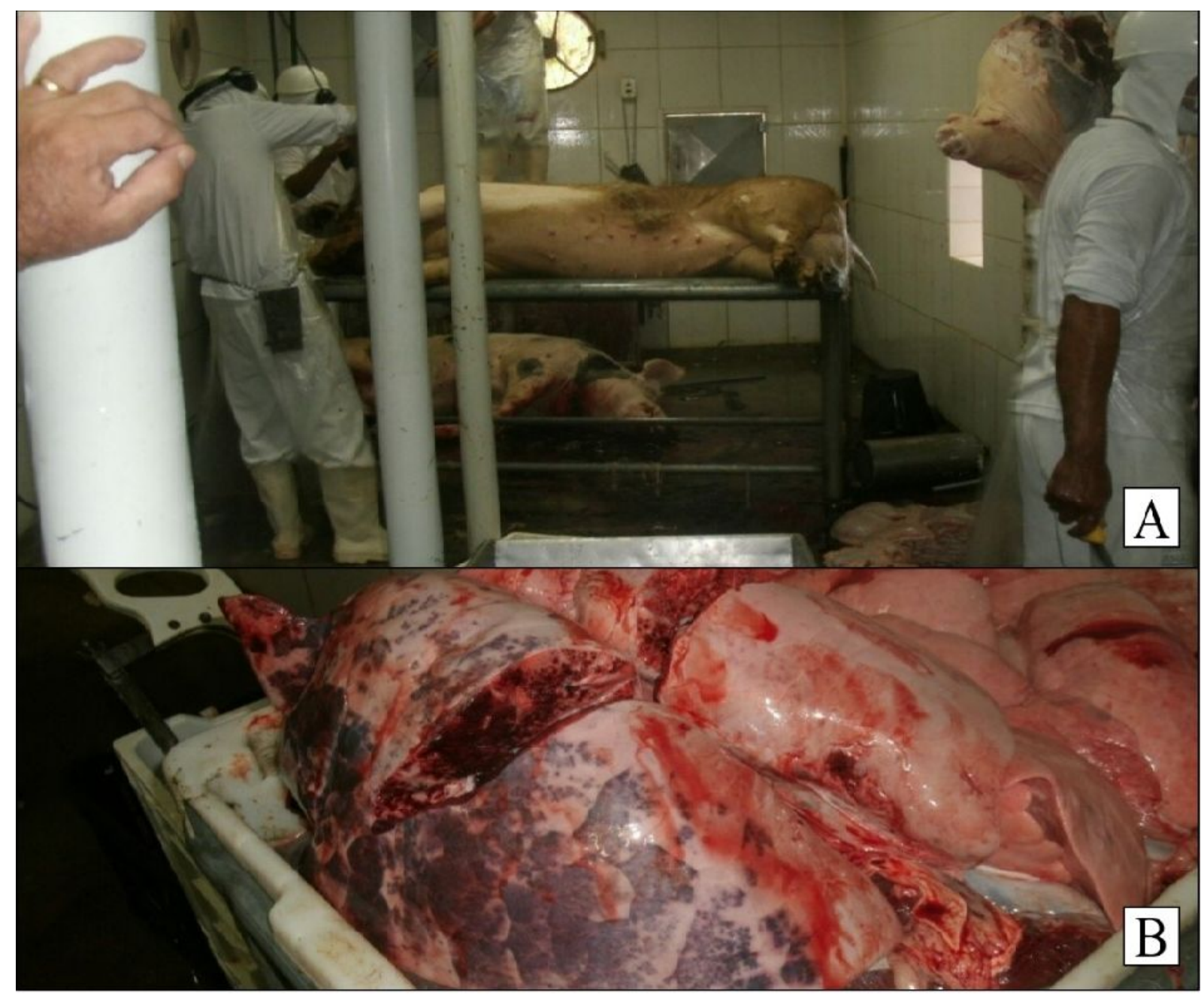

Já no estabelecimento com SIM (Fig. 3), observou-se que não houve cumprimento da Boas Práticas de Fabricação, além da falta de higiene no ambiente de uma forma geral, ausência de instrução sobre abate humanitário e procedimentos operacionais adequados, inexistência de médico veterinário e agentes de inspeção no local. Visitas periódicas destes profissionais também não eram realizadas. As carcaças eram carimbadas pelos próprios funcionários da linha de abate do matadouro. 
FIGURA 3- Abate de suínos sob Sistema de Inspeção Municipal no estado do Acre: A) Entrada do estabelecimento; B) Local de abate e demais procedimentos; C) Carcaça carimbada; D) Carimbo em recipiente inadequado.

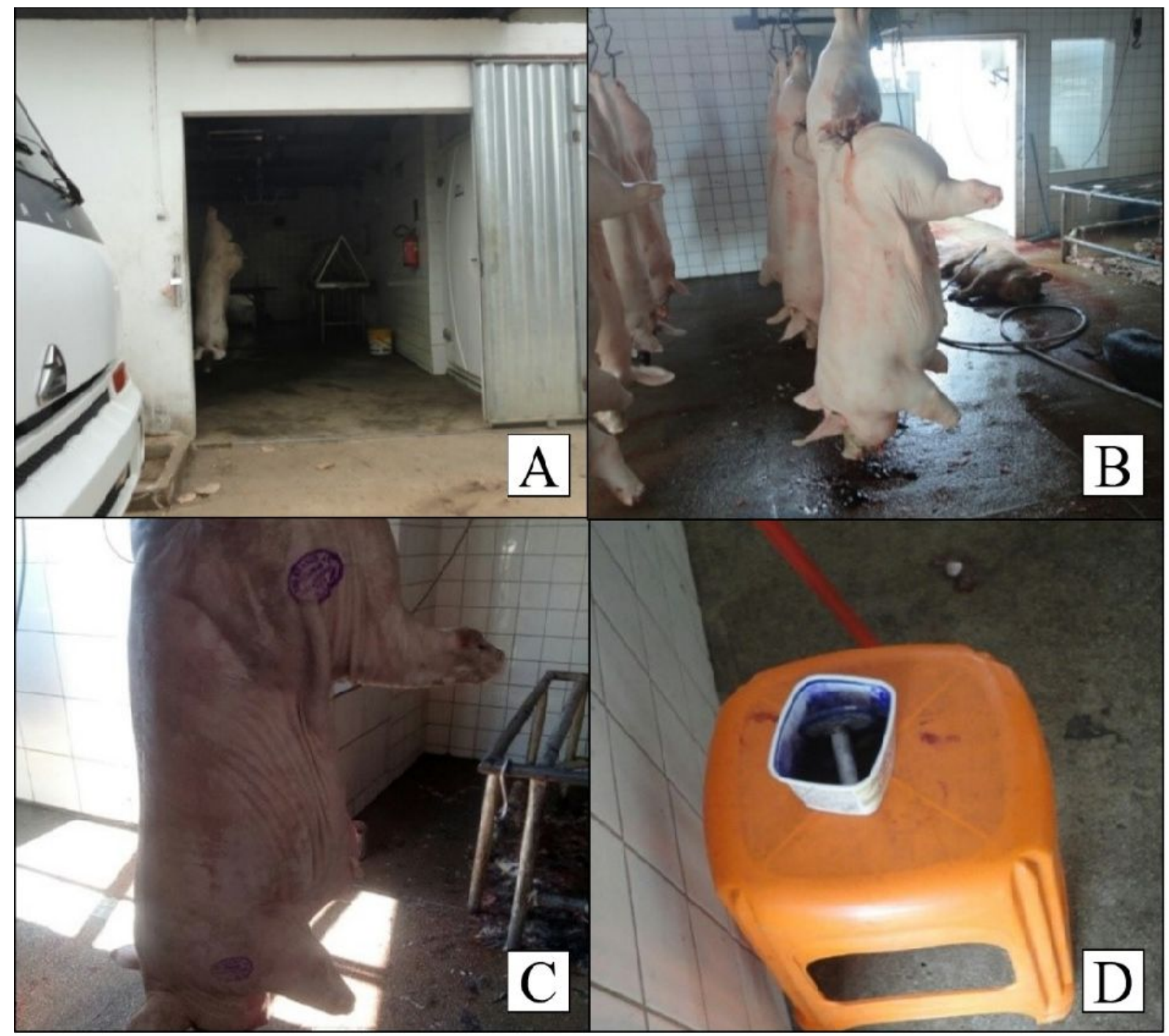

A principal alteração notificada pelo SIM (Fig. 4) foi a contaminação das vísceras brancas (estômago, intestinos, rins, bexiga, baço e pâncreas - 100\%), devido ao rompimento dos órgãos, à deposição dos mesmos sob o chão e à presença de moscas no local. Além disso, observou-se congestão pulmonar $(63,01 \%)$, aspiração pulmonar $(45,20 \%)$, petéquias na carcaça $(24,65 \%)$ e no baço $(5,47 \%)$. 
FIGURA 4- Alterações macroscópicas notificadas pelo Sistema de Inspeção Municipal no estado do Acre: A) Vísceras gastrointestinais em contato direto com o chão; B) Enfisema pulmonar; C) Aspiração e congestão pulmonar; D) Petéquias na carcaça.

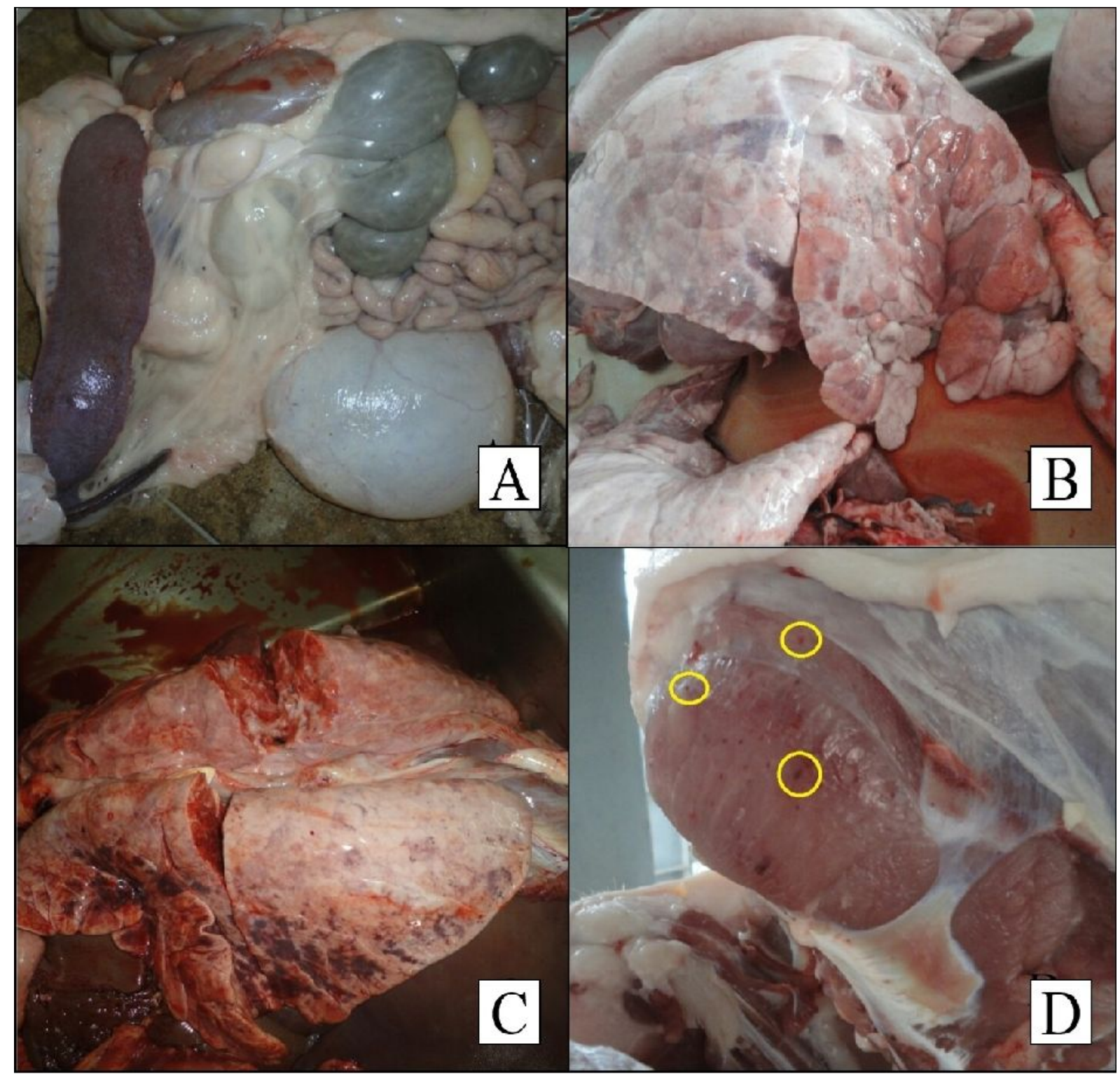

Neste último estabelecimento, não existia um fluxograma de abate a se seguir e todos os procedimentos eram realizados em um mesmo espaço, sem os cuidados higiênico-sanitários. Realizava-se a junção de todas as vísceras brancas no chão e as vísceras vermelhas em uma mesa de inox. Observou-se ainda o contato direto das peças com o manipulador (Fig. 5). 
FIGURA 5- Fatores relacionados à contaminação notificada pelo Sistema de Inspeção Municipal no estado do Acre: A) Presença de madeira; B) Presença de mosca e contato direto entre as carcaças; C) Depilação incorreta; D) Contato direto da mão do manipulador com a carcaça; E) Não oclusão do reto.

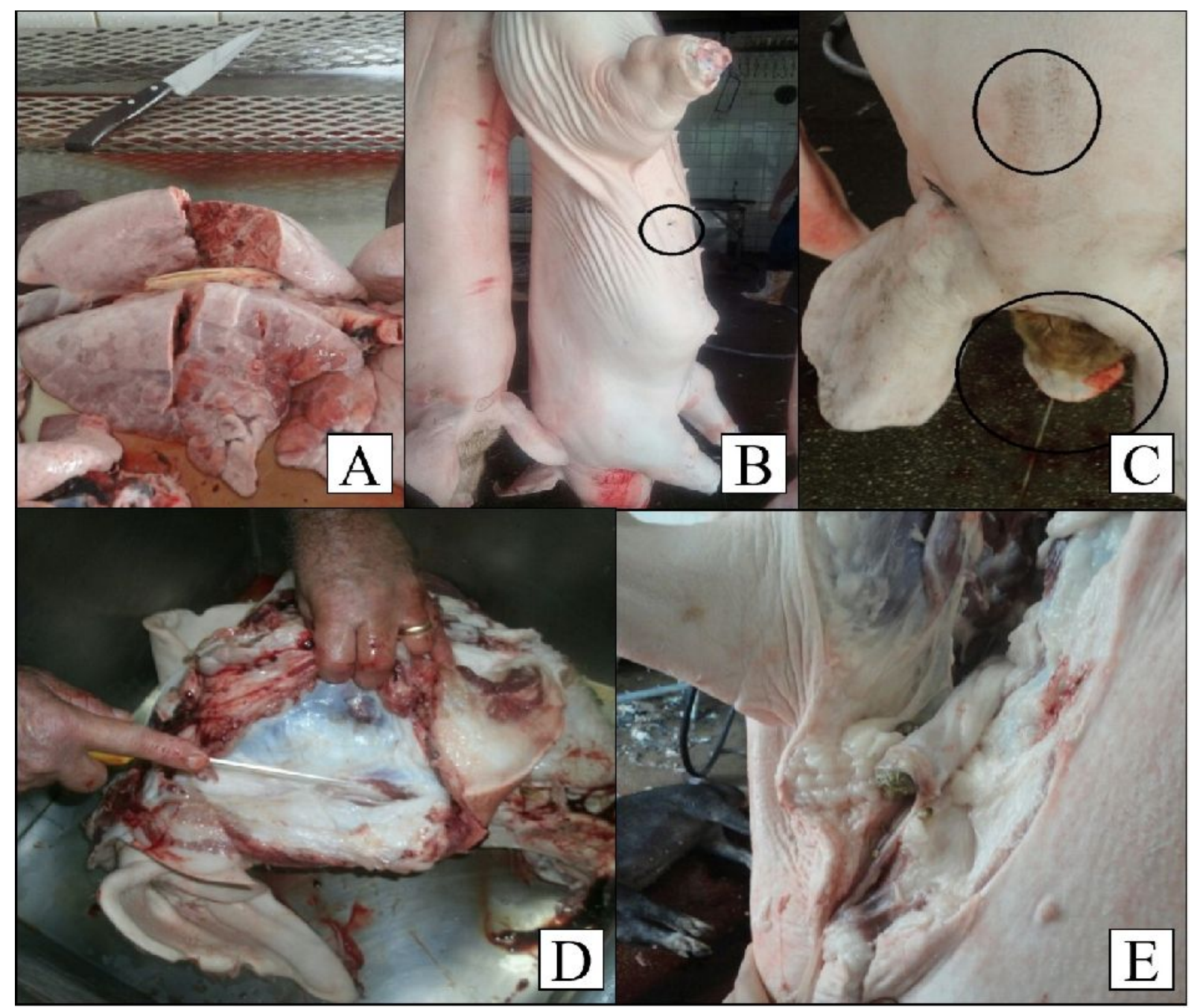

\section{DISCUSSÃO}

No estabelecimento com SIF, foram verificadas mais alterações macroscópicas nas peças, quando comparado com os demais serviços de inspeções. O papel de um médico veterinário é de fundamental importância para o julgamento de carcaças e vísceras de acordo ao exame ante-mortem, às condições sanitárias dos procedimentos de abate e do frigorífico. A ausência destes profissionais permite a falta do julgamento e condenação de produtos inadequados, trazendo riscos eminentes à saúde pública (RAMOS; GOMIDE, 2017).

As falhas técnicas nos abatedouros de suínos no estado do Acre são possivelmente negligenciadas, assim, a oferta de carne suína para o mercado consumidor é atendida, mas nem sempre o produto final pode ser considerado inócuo. A fiscalização de estabelecimentos de produtos de origem animal deveria ser sistemática, rigorosa e padronizada, conforme propõe o Regulamento de Inspeção Industrial e Sanitária de Produtos de Origem Animal (BRASIL, 2017), contudo, a situação de alguns abatedouros denota um controle inadequado dos procedimentos (EMBRAPA, 2019). 
Embora houvesse a presença de agentes de inspeção no estabelecimento com SIE, o reduzido número de lesões observadas pode ter relação com a baixa quantidade de animais abatidos no período de estudo. As causas de contaminações nos abatedouros sob SIE e SIM foram distintas do abatedouro federal e ocorreram em maior porcentagem, em decorrência de fezes por não oclusão do reto, contaminações cruzadas, presença de mosca e de sujidades. Fellows (2018) cita como fatores em potencial do processo de contaminação da carcaça as condições de limpeza do ambiente de abate, a presença de moscas, poeira, água poluída, o contato com as mãos do operador e os equipamentos mal higienizados.

Falhas de operações, como não oclusão do reto e evisceração mal realizada, são responsáveis pela contaminação da carcaça suína por bactérias. A evisceração é a principal etapa do controle higiênico-sanitário para que não ocorram contaminações, principalmente por fezes e rompimento de vísceras com alguma patologia. Por meio da correta oclusão do reto, pode-se minimizar a contaminação por Yersinia entecolitica em 10\% e Salmonella sp. em 75\% (PIVOTTO et al., 2015).

Quanto às alterações anatomopatológicas, lesões no pulmão foram os principais achados nos estabelecimentos sob o SIE e o SIM. A aderência pulmonar e a pneumonia são sugestivas de pneumonia enzoótica por Mycoplasma hyopneumoniae (ABILLEIRA et al., 2010; MORÉS et al., 2015; BRETAS et al., 2018). Já a aspiração e congestão pulmonar, por sua vez, estão associadas ao estresse agônico, sendo uma tecnopatia decorrente de uma incisão profunda dos grandes vasos, atingindo a traquéia (ALENCAR et al., 2011). Animais mal insensibilizados e abatidos por incisão da veia jugular de forma cruenta irão apresentar achados indicativos de morte agônica e refletem o desconhecimento sobre o abate humanitário entre os magarefes (BRASIL, 2010; EDINGTON et al., 2018).

A presença de petéquias na carcaça, por sua vez, é proveniente do estresse e da agitação em grupo, ocasionados por procedimentos dolorosos, a exemplo da utilização de bastão elétrico durante a condução dos animais, longo período de aplicação do eletrodo, várias aplicações e uso de corrente elétrica em baixa frequência (RICCl; COSTA, 2015). Outro fator que contribui à ineficiência do sistema operacional e sanitário de determinados estabelecimentos se relaciona ao transporte inadequado de animais, propiciando a ocorrência de fraturas (FRUET et al., 2013; SEBRAE, 2016).

Diante desta avaliação preliminar do serviço de inspeção da carne suína no estado do Acre, acredita-se que para o destino adequado dos produtos e subprodutos de origem animal nos abatedouros, além da padronização operacional e implantação de Boas Práticas de Fabricação (FAO, 2017), é extremamente relevante a presença do médico veterinário no controle de todo o processo de abate e no efetivo julgamento das carcaças e órgãos, garantindo a inocuidade da carne suína para a população (RAMOS; GOMIDE, 2017).

\section{CONCLUSÃO}

Conclui-se que existe uma intensa disparidade higiênico-sanitária entre os estabelecimentos de abate de suínos sob inspeção federal, estadual e municipal do estado do Acre, e que não existe padronização rígida quanto aos procedimentos operacionais durante 0 abate nos estabelecimentos de inspeção sanitária estadual e municipal, podendo comprometer a inocuidade dos produtos cárneos de suínos. 


\section{REFERÊNCIAS}

ABILLEIRA, F.; MUSSKOPF, G.; FAUTH, E.; SILVA JUNIOR, V. B.; SCARTEZZINI, M.; VOGT, F. I.; OLIVEIRA, S. J. Análise bacteriológica de casos de aderência pulmonar em suínos abatidos em um frigorífico no Rio Grande do Sul. Revista Brasileira de Higiene e Sanidade Animal, v. 4, n. 1, p. 16-22, 2010. Disponível em: http://www.higieneanimal.ufc.br/seer/index.php/higieneanimal/article/download/29/21 14. Acesso em: 20/03/20.

ACRE. Instituto de Defesa Agropecuária e Florestal - IDAF/AC. Dom Porquito transforma produtores rurais no Alto Acre. 2016. Disponível em: http://www.idaf.ac.gov.br. Acesso: 23/01/20.

ALENCAR, A.S; FARIAS, M.P.O.; ROSAS, E.O.; LIMA, M.M.; MENEZES, M.M.; SANTOS, F.L.; ALVES, L.C.; FAUSTINO, M.A.G. Manejo higiênico-sanitário e lesões pulmonares em suínos na Região Metropolitana de Recife e Zona da Mata de Pernambuco, Brasil. Semina: Ciências Agrárias, v. 32, n. 3, p. 1111-1122, 2011. DOI: $\quad 10.5433 / 1679-0359.2011 v 32 n 3 p 1111 . \quad$ Disponível em: http://www.uel.br/revistas/uel/index.php/semagrarias/article/view/6143/8385. Acesso em: 09/01/20.

BRASIL. Ministério da Agricultura, Pecuária e Abastecimento. Circular no 175, de 16 de maio de 2005. Procedimentos de Verificação dos Programas de Autocontrole. Circular № 175/2005/CGPE/DIPOA. Brasília, 2005.

BRASIL. Ministério da Agricultura, Pecuária e Abastecimento. Decreto no 9.013, de 29 de março de 2017. Regulamento de Inspeção Industrial e Sanitária de Produtos de Origem Animal (RIISPOA), Brasília, DF, 2017.

BRASIL. Ministério da Agricultura, Pecuária e Abastecimento. Instrução Normativa n.03, de 17 de janeiro de $\mathbf{2 0 0 0}$. Aprova o regulamento técnico de métodos de insensibilização para abate humanitário de animais de açougue. Diário Oficial da República Federativa do Brasil, Brasília, DF, 18 jan. 2000.

BRASIL. Ministério da Agricultura, Pecuária e Abastecimento. Portaria $\mathbf{n}^{\circ} \mathbf{7 1 1}$, de 01 de novembro de 1995. Aprova as normas técnicas de instalações e equipamentos para abate e industrialização de suínos. Diário Oficial da República Federativa do Brasil, Brasília, DF, 03 de novembro de 1995.

BRASIL. Ministério da Agricultura, Pecuária e Abastecimento. Portaria $\mathbf{n}^{\circ}$ 326, de 30 de julho de 1997. Aprova o Regulamento Técnico; "Condições Higiênico-Sanitárias e de Boas Práticas de Fabricação para Estabelecimentos Produtores/Industrializadores de Alimentos". Diário Oficial da República Federativa do Brasil, Brasília, DF, 1997.

BRETAS, A.A.; PERDONCINI, G.; WILLEMANN, M. Prejuízos econômicos por condenação de vísceras vermelhas de suínos abatidos em Santa Catarina. PUBVET, v. 12, n. 6, p.1-13, 2018. DOI: 10.22256/pubvet.v12n6a120.1-13. Disponível em: https://www.pubvet.com.br/uploads/a0c5509bf2c2f62fab7a01f6460e18ab.pdf. Acesso em: 09/01/20. 
COSTA, R. A.; LEITE, P. A. G.; BARROS, C. G. G.; LOPES, B. M. G. Principais Causas de Condenações em Vísceras Comestíveis de Suínos Abatidos em um Matadouro Frigorífico Sob Inspeção Estadual na Região de Alagoinhas-BA. Veterinária e Zootecnia, n. 21, v. 4, p. 616-623, 2015. Disponível em: https://www.bvs-vet.org.br/vetindex/periodicos/veterinaria-e-zootecnia/21-(2014)4/principais-causas-de-condenacoes-em-visceras-comestiveis-de-suinos-aba/. Acesso em: 12/02/20.

EDINGTON, L.N.; MARQUES, J.A.; CRUZ, A.L.; BENTES, R.M.; MASCARENHAS, M.T.V.L.; MACÊDO, J.T.S.A.; NASCIMENTO, K.A.; PEDROSO, P.M.O. Eficiência das operações de insensibilização e sangria no abate humanitário de suínos. Revista Brasileira de Higiene e Sanidade Animal, v. 12, n. 1, p. 21-29, 2018. DOI: 10.5935/1981-2965.20180003. Disponível em: http://higieneanimal.ufc.br/seer/index.php/higieneanimal/article/view/424/2288.

Acesso em: 03/01/20.

EMBRAPA - EMPRESA BRASILEIRA DE PESQUISA AGROPECUÁRIA. Modernização da inspeção sanitária em abatedouros de suínos - Inspeção baseada em risco. Concórdia: Embrapa Suínos e Aves, 2019. 178p. Disponível em: https://www.infoteca.cnptia.embrapa.br/infoteca/bitstream/doc/1111408/1/final9146.p df. Acesso em: 01/02/20.

FELLOWS, P.J. Tecnologia do Processamento de Alimentos: Princípios e Prática. 4 ed. São Paulo: Artmed, 2018.

FAO - FOOD AND AGRICULTURE ORGANIZATION. Producción y sanidad animal. Buenas Prácticas para la Industria de la Carne. Organización de las Naciones Unidas para la Agricultura y la Alimentación, Fundación Internacional Carrefour, Roma, 2007.

FRUET, A. P. B.; SCORTEGAGNA A.; FABRICIO, E. A.; KIRINUS, J. K.; DÖRR, A. C.; NÖRNBERG, J. L. Perdas econômicas por condenação de órgãos suínos em matadouros sob serviço de inspeção municipal. Revista Eletrônica em Gestão, Educação e Tecnologia Ambiental, v. 11, n. 11, p. 2304-2312, 2013. Disponível em:

https://www.researchgate.net/profile/Edom_Fabricio/publication/271104080_PERDA S_ECONOMICAS_POR_CONDENACAO_DE_ORGAOS_SUINOS_EM_MĀTADOU ROS_SOB_SERVICO_DE_INSPECAO_MUNICIPAL/links/5a8d6d30458515ca91988 a56/PERDĀS-ECONOMICĀS-POR-CONDDENACAO-DE-ORGAOS-SUINOS-EMMATADOUROS-SOB-SERVICO-DE-INSPECAO-MUNICIPAL.pdf. Acesso em: 05/01/20.

IBGE -INSTITUTO BRASILEIRO DE GEOGRAFIA E ESTATÍSTICA. Indicadores do IBGE: Estatística da Produção Pecuária. 2018 Disponível em: http://www.ibge.gov.br/home/estatistica/indicadores/agropecuaria/producaoagropecu a-ria/abate-leite-couro-ovos_201601_publ_completa.pdf. Acesso em: 22/01/20.

MORÉS, M.A.Z.; OLIVEIRA FILHO, J.X.; REBELATTO, R.; KLEIN, C.S.; BARCELLOS, D.E.N.; COLDEBELLA, A.; MORÉS, N. Aspectos patológicos e microbiológicos das doenças respiratórias em suínos de terminação no Brasil. 
Pesquisa Veterinária Brasileira, v. 35 , n. 8, p. 725-733, 2015. Disponível em: http://www.scielo.br/pdf/pvb/v35n8/1678-5150-pvb-35-08-00725.pdf. Acesso em: 23/03/20.

PIVOTTO, M.; BRIZIO, A. P.; CASTRO, L. C. Redução da contaminação superficial de suínos: Um processo alternativo. Revista de Agricultura, v. 90, n. 1, p. 54-62, 2015. http://www.fealq.org.br/ojs/index.php/revistadeagricultura/article/view/94/63. Acesso em: 19/03/20.

RAMOS, E.M.; GOMIDE, L.A.M. Avaliação da Qualidade de Carnes Fundamentos e Metodologias. 2 ed. Viçosa, UFV, 2017. 473p.

RICCI, G.D.; COSTA, O.A.D. Abate humanitário de suínos. Revista de Ciências Agroveterinárias, v. $14, \quad$ n. 3 , p. 267-272, 2015. Doi: 10.5965/223811711432015267. Disponível em: http://revistas.udesc.br/index.php/agroveterinaria/article/view/223811711432015267. Acesso em: 11/02/20.

ROUQUAYROL, M.Z.; GURGEL, M. Epidemiologia e Saúde. 8 ed. Rio de Janeiro: MedBook, 2017. 744p.

SEBRAE - SERVIÇO BRASILEIRO DE APOIO ÀS MICRO E PEQUENAS EMPRESAS. Bem estar animal na produção de suínos: frigorífico. Brasília-DF, ABCS-SEBRAE, 2016. 38p. Disponível em: http://www.agricultura.gov.br/assuntos/producao-animal/arquivos-publicacoes-bemestar-animal/cartilha-embrapa-abcs-mapa-sebrae-bem-estar-no-frigorifico.pdf. Acesso em: 18/02/20. 